\title{
THE FONTÉCHEVADE SKULLS AND THE ORIGIN OF HOMO SAPIENS
}

$\mathrm{T}$ HE long-awaited full report on the human remains from the Fontéchevade Cave (Charente) in south-western France, where in August 1947 the fragmentary skulls of two individuals associated with a Tayacian industry were discovered by Mlle G. Henri-Martin, has now been published*. The palæontological and chemical evidence of their age, taken in conjunction with that of archæology and stratigraphy, points to an early part of the RissWürm interglacial-some authorities favour the Riss glaciation itself-or a time preceding the advent of the Mousterian culture associated with Neanderthal man. Fontéchevade I consists of a small piece of the glabellar region of the frontal bone, and Fontéchevade II, which has been affected by burning, of almost the whole left parietal, the upper half of the right parietal, and the upper portion of the frontal.

Prof. H.-V. Vallois concludes that Fontéchevade I belonged to an adult subject of probably female sex. It is slightly thicker than the corresponding region in modern European frontals and does not show any marked development of the glabella, its most characteristic feature for so ancient a specimen being the complete absence of a supra-orbital torus. His study of Fontéchevade II is lengthy and thorough, involving comparisons of separate characters with those of Lower and Middle Palæolithic fossil skulls from Europe and western Asia. In this the defective state of the specimen necessitated the making of assumptions in the reconstruction of certain missing regions. According to Prof. Vallois, its owner was probably male and 50-60 years old at the time of death. The cranial capacity he determines from one of the Lee-Pearson reconstruction formulæ based on calvarial length, breadth, and auricular height (measured from the biporial axis to the apex and not, as erroneously stated in Rudolf Martin's "Lehrbuch der Anthropologie", to the bregma), less $50 \mathrm{~cm}^{3}$ as an allowance for exceptional thickness of bone, to be $1,470 \mathrm{~cm} .^{3}$. A preferable formula would seem to be the corresponding one of Hooke ${ }^{1}$, used by Morant to estimate the capacity of the Swanscombe skull ${ }^{2}$, which, with the same deduction as before, yields an even higher figure of about $1,550 \mathrm{~cm} .^{8}$ for Fontéchevade II. However, the arbitrary nature of such estimates from incomplete material must be stressed. The dimensions of the skull are in any event considerable. As seen from above, the vault is pentagonal, the greatest breadth is situated at a low level, and the biasterionic diameter has a high value. The frontal bone, like that of Fontéchevade I, apparently lacks a torus and has no post-orbital constriction. There is an absence of parietal foramina, which it shares with the majority of the more ancient representatives of fossil man.

The fourth chapter of Prof. Vallois's monograph is an attempt to assess the taxonomic position of the Fontéchevade Tayacians, whom he now compares en bloc first with three different 'Neanderthal' groups,

* Archives de l’Institut de Paléontologie Humaine, Paris. Mémoire 29: La Grotte de Fontéchevade. Deuxième partie: Anthropologie. Par Henri-V. Vallois. Troisième partie : Géologie et Paléontologie. Par $\mathbf{H}$. Alimen, C. Arambourg et A. Schreuder, avec la collaboration de G. Henri-Martin, J. Berlioz et J. Bouchud. Pp. $262+6$ planches. (Paris: Masson et Cie., 1958.) namely, the 'classic' Neanderthals of the last or Würm glaciation in Europe, the pre-Neanderthals of the same continent, including the Ehringsdorf and the two Saccopastore skulls, all from the RissWürm interglacial, and the Steinheim skull, probably of Rissian age, and the Palestinian Neanderthaloids, dating from the Riss-Würm or the Würm I-II interstadial; then with European fossil Homo sapiens; and finally with the Swanscombe skull from the Mindel-Riss. So far as the classic Neanderthals are concerned, Prof. Vallois points out numerous distinctions between these and the Fontéchevade skulls, a categorical one being the form of the forehead and in particular the absence of a supra-orbital torus in the Tayacians, a feature also separating them from the remaining two 'Neanderthal' groups treated by him. He replies to critics who, broadly speaking, are unconvinced that the Fontéchevade fragments can be distinguished in any definitive way from the preNeanderthals of Europe, and stresses the close resemblance that exists between Fontéchevade II and the Swanscombe skull.

Prof. Vallois then devotes a substantial portion of his text to the 'Presapiens' concept, that is to say, the reasons in favour of the existence of a line of fossil men who, while more ancient than the classic Neanderthals, nevertheless differ from them and from the preNeanderthals in the complete absence of a supra. orbital torus and display in this and other characters an approach to Homo sapiens. He discusses in turn the development of this concept and the claims for various finds to be included in the 'Presapiens' category. Briefly, only three individuals qualify, the two from Fontéchevade and the Swanscombe skull, of which the frontal bone is missing. He next considers the argument that the Swanscombe skull, if its frontal were present, could have been furnished with a torus as developed as that of the almost contemporary Steinheim skull, a suggestion first made by Morant, who pointed out the similarity in bone thickness and in the conformation of the occiput between Swanscombe and Steinheim. A provisional diagnosis of 'Presapiens', based on the traits of the Fontéchevade and Swanscombe skulls, is followed by the statement that it represents a primitive form of Homo sapiens, from which 'Presapiens' was probably not specifically distinct and of which it ought logically to be considered as an initial stage.

In his fifth chapter Prof. Vallois reviews the theories of the origin of Homo sapiens, which he classes under three main heads : (1) direct derivation from classic Neanderthal man, (2) derivation frompre-Neanderthals, and (3) derivation from a source independent of either, that of 'Presapiens'. The essentials of the case for each are set forth with the lucidity and encyclopredic knowledge of which the author is so remarkable an exponent. Naturally enough, the solution that he himself favours is the third one, that which envisages a separation of the lines leading respectively to Homo sapiens and to the classic Neanderthals in the Lower Pleistocene and perhaps no earlier than its post-Villafranchian phase.

Presented though they are with the skill and authority that Prof. Vallois commands, the arguments 
in support of the 'Presapiens' thesis, as expounded by him, have had a mixed reception among students of human palæentology. Thus the veteran Prof. Sergio Sergi, in a paper devoted to the Swanscombe and Fontéchevade remains ${ }^{3}$, emphasizes the uncertainty of an adequate morphological diagnosis from them owing to their incompleteness. While acknowledging that they possess some traits in common with Homo sapiens such as the absence of a supra-orbital torus in Fontéchevade and certain metrical features in Swanscombe, he believes that their platycephaly, great biasterionic diameters, and posterior expansion of the base of the parietals are structurally archaic features the importance of which has been underestimated. In other words, it is not possible to recog. nize different pre-Neanderthal and 'Presapiens' groups much before the Wuirm. For Sir Wilfrid Le Gros Clark the morphological traits of Swanscombe and Fontéchevade as well as those of other European fossils, for example, Steinheim, Ehringsdorf, Krapina and Saccopastore, do not justify their specific separation from Homo sapiens ${ }^{4}$. This view, then, while acknowledging the sapient features of Swanscombe and Fontéchevade, does not differentiate them taxonomically from forms which Prof. Vallois would classify as pre-Neanderthals, and it regards classic Neanderthal man as comprising an aberrant evolutionary line which left the precursors of modern man when they had already attained a stage at which they were indistinguishable from Homo sapiens.

J. C. Trevor

${ }^{1}$ Biometrika, 18, 1 (1926).

${ }_{2}, J$. Roy. Anthrop. Inst., 68, 67 (1938).

${ }^{3}$ Riv. Antrop., 40,65 (1953).

" "The Fossil Evidence for Human Evolution" (Chicago, 1955)

\section{PLANT ECOLOGY OF ANCIENT PERIODS}

$\mathrm{T}$ HREE palæobotanists contributed papers to a symposium on palæoecology held at the Linnæan Society on March 19. They agreed on a wide definition of ecology, being ready to include almost anything that could be learnt from plant fossils, apart from their taxonomy and their morphology. After that, each speaker went his own way and confined himself to material he had studied in both the field and laboratory.

Dr. Kathleen Chesters spoke about the Tertiary floras of the coastal parts of Kent, Sussex, Hampshire, Dorset and Devon. She emphasized how difficult collecting has now become in this stretch of coast; and also dealt with the cliffs of Mull, where one can do little without explosives (Starkie Gardener, the pioneer, used dynamite). She dealt mainly with the nature and validity of evidence; apart from deductions from geology and from fossil animals, we have two main kinds of evidence from plants.

First, there is ecological form and ecological anatomy. The plant world of the Tertiary seems so like our own, and plants appear to have changed so little that we can reasonably use arguments based on the modern plant world. For example, we know that the proportion of trees with leaves (or leaflets) with entire margins increases from cool climates to the tropics. Then, also, leaves with drip tips are much commoner in rainy than in dry climates. Growth rings in wood indicate seasonal growth, and to-day, usually a winter resting season. All this evidence is available without a specific or generic determination, but where there is such determination it is possible and legitimate to inquire in what climatic zones most of the genera flourish to-day; or even in what country they are found. Where both lines of evidence coincide, as in general they do, one has impressive evidence. Dr. Chesters briefly made a case for likening the Eocene floras to those of Malaya, but the Mull flora (not yet securely dated) to the warm temperate floras of China and Japan.

Prof. T. M. Harris (Reading) said that the corresponding arguments were largely useless in the Jurassic because nothing like the Jurassic flora exists anywhere on earth. A quarter of the species belong to extinct families and the rest to relic families (like Gingko and Thyrsopteris and Matonia). Gymnosperm leaves are too different from those of angiosperms to allow reasonable comparison of their ecological form, and he suggested that the more tender ones were simply deciduous and the tough ones evergreen. $\mathrm{He}$ could not answer reasonable questions about past climates, but could only supply unexpected ecological crumbs, such as that forest fire was widespread and rather frequent in the Jurassic.

In the Yorkshire Deltaic flora the frequency of ferns might indicate a humid atmosphere, but the rarity of epiphytes rather suggests dryness. He showed that the Delta included three floras, swamps of Equisetum, often preserved intact; trees and herbs of the river banks represented by detached leaves but nowhere preserved as they grew, and, finally, tiny plant fragments. These last are the most varied, numerous and widespread and may represent floras of inland habitats washed down by occasional floods.

Dr. W. S. Lacey (Bangor) dealt with his recent experiences when collecting in the Karoo series of the Upper Zambezi in Southern Rhodesia. He drew more on geological evidence than the previous speakers. This great series of inland origin extends from the Upper Carboniferous to the Jurassic. It begins, as in South Africa, with Dwyka glacial deposits (tillites and varved clays), but farther north in Nyasaland there is no glacial deposit but only torrent-carried boulders.

The earliest floras are too little known to be useful, but the succeeding rich flora of Upper Wankie sandstone and the $40-\mathrm{ft}$. thick coal seam are taken to indicate good conditions for plant growth. The admixture of Glossopteris, Gangamopteris and of Northern (mostly European) Upper Carboniferous or Lower Permian species was also held to indicate warmth, since they are supposed to have lived in a very warm climate in Europe. Later stages, though still with a rich Glossopteris flora, have lost both the genus Gangamopteris and the Northern species. They are followed by Triassic floras with Dicroidium and the conifer-like Dadoxylon the growth rings of which seem significant. Still later there are freshwater concretionary limestones which may indicate evaporating lakes, and finally extensive fossil sand dunes indicating a hot, dry desert.

Dr. Lacey said he hesitated to regard Gangamopteris as an indicator of a glacial or even cold climate. He 